\title{
ESTRATEGIA Y MERCADO DE TECNOLOGÍA: TIPOLOGÍA DE EMPRESAS INNOVADORAS ANDALUZAS ${ }^{1}$
}

\section{STRATEGY AND TECHNOLOGY MARKET: TYPOLOGY OF ANDALUSIAN INNOVATIVE COMPANIES}

Recibido: marzo, 2012.

\author{
Reyes González Relaño \\ Universidad de Sevilla \\ rgrelano@us.es
}

Versión final aceptada: enero, 2013.

PALABRAS CLAVE: empresa innovadora, compra y venta de tecnología, estrategia tecnológica, análisis clúster.

KEYWORDS: innovative company, buying and selling technology, technology strategy, cluster analysis.

\section{RESUMEN}

El artículo estudia el papel que desempeñan las empresas innovadoras de Andalucía en el mercado tecnológico y reconoce si éstas siguen una Estrategia Tecnológica como instrumento que marca los objetivos y directrices a seguir en relación al uso de la tecnología. Se ha realizado un proceso de encuestación a 201 empresas innovadoras andaluzas que compran y/o venden tecnología a cuyos datos se ha aplicado un método mixto de análisis clúster. Se han identificado seis tipos de empresas en función de su posición en el mercado, de los rasgos sectoriales y territoriales, del alcance geográfico de las relaciones y de la dotación de habilidades, capacidades y recursos internos para la innovación. Predominan las relaciones de compra de tecnología en el exterior de Andalucía mientras que la venta, de alcance regional, es aún muy reducida.

\footnotetext{
${ }^{1}$ Este artículo forma parte de los resultados del Proyecto "Estrategia de innovación empresarial. Comportamientos territoriales" del Plan Nacional I+D+i del Ministerio de Economía y Competitividad (2012-2014). REF: CO 2011-26125.
}

ISSN: 0212-8594 ISSN-e: 2340-2776 № DOI: http://dx.doi.org/10.12795/rea.2012.i29.06 REA 29 (2012):127-157 


\section{ABSTRACT}

This paper analyzes the role played by innovative companies of Andalusia in the technology market and recognizes if they follow a Technological Strategy as a tool that sets the goals and guidelines to be followed in relation to the use of technology. We performed a survey process to 201 Andalusian innovative companies buy and / or sell technology whose data were analyzed with a mixed method of cluster analysis. Six types of companies have been identified basing on their position in the market, sectorial and territorial traits, the geographic scope of the relationship and the provision of skills, capabilities and internal resources for innovation. The technology procurement relationships abroad are predominating, while the sale of technology is reduced and regional. 


\section{INTRODUCCIÓN.}

En las últimas décadas el uso masivo de tecnologías avanzadas como elementos clave para la modernización, el desarrollo acelerado de nuevos actores económicos por un lado y la incidencia de la crisis económica en otros, además de la consolidación de la globalización de los procesos productivos (fundamentados en la continua introducción de avances científicos y tecnológicos) han acentuado la capacidad innovadora del territorio como principal factor de desarrollo y crecimiento económico (Rezzónico, $R, y$ Muñoz, G. 2009; Porter, M. 2009; Glaeser, E. y Berry, C., 2005).

Así también se argumenta desde la Geografía y, en general, desde las Ciencias Sociales (Boshma, R., 2005; Boshma, R. y Fritsch, M., 2009; Jordá,R. y Ruíz,F., 2010; Boggio y Dematteis, 2002; Porter, 2009) que el cambio estructural de las economías pasa en la actualidad por centrarse en unas condiciones de crecimiento impulsado por la innovación (OCDE, 2009b; UE, 2010; Pérez, F., 2011), cuyos efectos van a depender de cómo ésta se difunda en el tejido empresarial. De este modo, las instituciones públicas al más alto nivel (OCDE, 2009a; Comisión Europea, 2000) ponen en evidencia la necesidad de contar con un modelo de desarrollo abierto, competitivo y orientado hacia el exterior para poder conectar la internacionalización e innovación en un sistema complejo (Villar, C. et.al, 2012) de transferencia de recursos tecnológicos y científicos que favorezca el desarrollo del conocimiento.

En este contexto, formar parte del mercado de tecnología se ha convertido en un componente básico de la competitividad de las empresas y en uno de los elementos principales para su diferenciación (Huerta, E. y Salas, V., 2012; Santamaría, L. y Rialp, J., 2007) porque les facilita crear nuevos productos y/o procesos y les posibilita mejorar su capacidad comercializadora. De manera que la tecnología no debe entenderse como un mero instrumento (Hidalgo, A., 1999), sino que está constituida por los conocimientos y habilidades necesarias para la creación, mejora y utilización de las técnicas (Lucendo, A.L., 2009) y requiere de la aplicación del conocimiento científico y organizativo a tareas prácticas. Es un medio y a la vez un fin: un medio si se considera como parte del proceso que permite el desarrollo de productos innovadores; o un fin si la tecnología se encuentra embebida en el propio producto innovador.

Por ello la tecnología se concibe como conocimiento generado en un sistema abierto, dinámico y en permanente interacción, que implica la existencia de relaciones de compra y venta que genera interdependencias entre diferente agentes (COTEC, 2010). Pero no todas las empresas están capacitadas para incorporarse y participar activamente en el mercado de tecnología porque la habilidad de las firmas para explotar las fuentes externas de tecnología va a depender de su capacidad de absorción (Cohen, W. y Levinthal,D., 1990) y de transformación (Garud, R. y Nayyar, P., 1994). La primera facilita la identificación y asimilación del conocimiento válido del entorno. Mientras que la capacidad de transformación se define como la habilidad para redefinir la cartera de productos de la empresa en base a las oportunidades

ISSN: 0212-8594 ISSN-e: 2340-2776 № DOI: http://dx.doi.org/10.12795/rea.2012.i29.06 REA 29 (2012):127-157 
tecnológicas creadas por ella misma (Arora,A., et.al, 2001). Por lo que el proceso de introducción, adaptación y cambio tecnológico en la empresa exige complementariedad entre la adquisición externa y el desarrollo interno de actividades de I+D (Cassiman B., 2009, ONUDI, 1984) que se sustentan en recursos tangibles e intangibles (inversión económica, capital humano, capital técnico y organizacional) y experiencia previa. Y esta complejidad requiere de una óptima gestión por parte de las empresas ya que la velocidad del cambio tecnológico se ha acelerado debido al acortamiento del ciclo del desarrollo del producto y el incremento de su difusión espacial.

Por esta razón las empresas deben definir cómo desarrollar, adquirir y asimilar tecnología a través del diseño de una Estrategia Tecnológica (ET). Ésta debe concretar también el mecanismo para incorporar sus nuevos productos tecnológicos de forma eficaz y anticiparse a las necesidades de los clientes (Hidalgo, A., 1999). De este modo, tiene que ser concebida como la política a seguir para el desarrollo y el uso de la tecnología y debe incluir no sólo las actividades de investigación y desarrollo, sino también otra serie de aspectos internos (costes, calidad) y externos (rivalidad, acceso, etc.) por lo que resulta necesario integrarla en la estrategia global de la empresa.

En base a estas argumentaciones, la investigación analiza las relaciones de compra venta de tecnología en Andalucía partiendo de la concepción que el mercado regional de tecnología en esta Comunidad es aún muy reducido. Y esto se debe, entre otras causas, a que el nivel tecnológico de su tejido empresarial es bajo y predomina el uso de tecnología convencional, siendo pocas las firmas que aplican la de tipo experimental.

Para alcanzar este objetivo global se identifican 201 Empresas Innovadoras Andaluzas (EIA) que compran y/o venden tecnología de entre una muestra representativa de 263 firmas. Con esta muestra se realiza un análisis de la motivación y formulación de la estrategia tecnológica y se estudian los productos que intercambian en el mercado regional y exterior desde el punto de vista sectorial y territorial. Posteriormente, con las variables referentes a tres grandes bloques: empresa innovadora andaluza, empresa proveedora y empresa cliente de tecnología, se aplica el análisis clúster para identificar la tipología de firmas en base al papel que desempeñan en el mercado de tecnología regional y exterior.

\section{MARCO TEÓRICO, OBJETIVOS Y METODOLOGÍA.}

La OCDE (2005, 2009a, 2009b) indica que una de las fuentes principales de conocimiento para la actividad innovadora es el mercado tecnológico que abarca desde los proveedores pasivos de información hasta los suministradores de conocimiento y tecnología incorporada o desincorporada. En este sentido, los estudios empíricos efectuados en los últimos años (Malerba, F., 2004, Jordá,R., 2007, 2009; Boggio, F. y Dematties, G., 2002) revelan que en las regiones europeas menos 
favorecidas, el mercado tecnológico se caracteriza por la concentración territorial y/o sectorial en el que los efectos de la proximidad geográfica son parte importante de este fenómeno (Jordá, R. y Ruiz, F., 2012). Además, de manera reciente, debido a la aparición y desarrollo acelerado de nuevas regiones se ha incrementado la dispersión geográfica de las fuentes de tecnología y ello ha complejizado los vínculos y relaciones por los que fluyen estos productos (Jordá ,R. y Ruiz, F., 2010).

En este sentido, Noguera,J. y Esparcia,J., (2008) inciden sobre la idea que las relaciones entre diferentes agentes tecnológicos desempeñan un papel determinante en el desarrollo de un territorio. Su carencia puede suponer un freno a la transmisión de conocimiento, especialmente en un entorno donde predominan las pequeñas y medianas empresas. $\mathrm{Y}$, por el contrario, la participación en estos mercados tecnológicos puede contribuir a la difusión de las innovaciones, favoreciendo la competitividad y el dinamismo del territorio. Por lo que el papel que las regiones realicen en el mercado tecnológico está directamente relacionado con: a) la densidad, intensidad y la calidad de organización de estas en el espacio productivo regional Ruiz,F., 2005) ; y b) con la capacidad de apertura al exterior de la región. Ambas condiciones están vinculadas directamente con la naturaleza de las empresas y con el alcance geográfico y sectorial de su mercado (Dierkes, M., 2003; Alic, J.A., 1990; Amir, R., et.al. 2003; Jordá, R. y Ruiz, F., 2012).

Por otro lado y debido a que la tecnología adquirida (incorporada o desincorporada) y los spillover no se adaptan automáticamente al proceso innovador, una importante tarea de la gestión de la innovación en el seno de las empresas es integrar óptimamente los conocimientos externos a su proceso de innovación. Además, detrás de los contratos formales (compra venta de tecnología en el mercado) existen multitud de contratos informales (movilidad de personal, relaciones personales formales e informales) que son difíciles de cuantificar pero muy importantes y no pueden analizarse independientemente de la organización del proceso innovador. Para que todo ello funcione correctamente se requiere complementariedad con la I+D dentro de la empresa (Cassiman,B., 2009) y disponer de una serie de recursos y capacidades (Barney, J., 2002; Helfat, C., et.al. 2007) internas (técnicos, humanos y organizacionales), pues la introducción de productos nuevos o mejorados en el mercado exige poseer habilidades y experiencia previa en investigación y desarrollo que les facilite la absorción y adaptación del conocimiento adquirido.

Así que la introducción de nueva tecnología en la empresa no sólo representa la compra de un activo y su puesta en marcha, sino también la posibilidad de entablar nuevas relaciones técnicas, de adquirir nuevas competencias y de manejar nuevos conceptos (Vega-Jurado,J., et.al. 2009a, 2009b; Cassiman ,B., y Veugelers, R., 2006; Belderbos,R., et.al, 2006, 2004). Y en este sentido, el desarrollo interno y la adquisición externa de conocimiento pueden llegar a ser y deben ser acciones complementarias para promover el desempeño innovador de la empresa (Fernández de Lucio, J., et.al, 2008). De manera que la I+D interna cumple un doble papel: constituyen una fuente de conocimiento importante para la obtención de ideas 
innovadoras y paralelamente incrementa la capacidad de la empresa para identificar, asimilar y explotar el conocimiento disponible fuera.

Por estas razones el acceso y participación de las empresas en el mercado tecnológico (desde la venta o la compra) está condicionado fundamentalmente por el conocimiento base que poseen las firmas, los procesos de aprendizaje y por las complementariedades entre empresas. De manera que la posición científica y las diferencias sectoriales generan múltiples composiciones o tipologías de relaciones (Malerba ,F., 2005; Evangelista, R. y Matrostefano, V., 2006; Lucendo, A.L. y González, R., 2012) ya que el conocimiento puede ser más o menos acumulativo según el sector, demostrándose que cuando se posee una buena base en investigación y desarrollo, se incrementa las posibilidades de apropiarse de las innovaciones externas y de convertirse en proveedor tecnológico.

Así, atendiendo a las diferencias sectoriales, Cassiman, B. (2009) utilizando la clasificación sectorial de Pavitt, K. (1984) y Soete, L. y Miozzo, M., (2001)² sugiere que para las empresas dominadas por los proveedores el conocimiento está incorporado básicamente en máquinas, equipos y bienes producidos por empresas de otros sectores. Mientras que para las empresas basadas en la ciencia las principales fuentes de conocimiento son las actividades internas de I+D y la investigación científica lo que le permite ser proveedores tecnológicos.

\footnotetext{
2 Estos autores clasifican los sectores por los rasgos que tienen en sus formas de innovar (patrones de innovación/regímenes tecnológicos). Se distingue:

a) Dominados por los proveedores. Son aquellos en los que las empresas del sector desarrollan escasa actividad innovadora. Esta les llega incorporada en las materias primas y en la maquinaria y equipo que compran a sus proveedores. Fundamentalmente realizan diseño. Se encuentran en este grupo el textil, las prendas de vestir y peletería, madera y corcho, cartón y papel, muebles, cuero, calzado, edición, impresión y reproducción y otras industrias manufactureras. Servicios: educación, sanidad, administración pública, servicios personales (reparaciones, peluquerías, etc), comercio al por menor.

b) Productores a gran escala. En estos sectores la innovación se centra en la aplicación de la estrategia de reducción de costes ya que elaboran productos destinados a grandes mercados con un determinado grado de estandarización. Forman parte de este grupo: industrias extractivas, alimentación, refinado de petróleo, minerales no metálicos, manufacturas metálicas, automóviles, naval, otro material de transporte, tabaco, metales férreos y no férreos, electricidad, gas y agua. Servicios: servicios de electricidad, gas y agua, servicios de transporte y viaje y comercio al por mayor.

c) Proveedores especializados. Las empresas en este grupo llevan a cabo desarrollos propios y se mantienen estrechamente ligadas al proceso innovador de sus proveedores y de sus clientes. Se sitúan en este grupo la maquinaria de oficina y ordenadores, maquinaria mecánica y electrónica. Servicios: banca, seguros, radiodifusión y servicios de telecomunicación.

d) De base científica. Son sectores en los que su innovación se basa esencialmente en un elevado nivel de investigación propia. En este grupo se encuentran: farmacia, productos químicos, caucho y plástico, componentes electrónicos, aparatos de radio, TV, las telecomunicaciones, óptica, instrumentos de precisión y relojería, la industria aeronáutica y aeroespacial. Servicios: servicios y laboratorios de I+D, ingeniería, software, diseño, consultoría.
}

ISSN: 0212-8594 ISSN-e: 2340-2776 № DOI: http://dx.doi.org/10.12795/rea.2012.i29.06 REA 29 (2012):127-157

http://www.publius.us.es/estudios_andaluces 
En este entramado de relaciones tecnológicas, desde el punto de vista territorial ${ }^{3}$, las ciudades y sobre todo las aglomeraciones urbanas desempeñan un papel fundamental puesto que generan externalidades derivadas de los flujos de conocimiento que allí se concentran, fomentan la internacionalización de las empresas y la capacidad para establecer relaciones con el exterior y de ahí extenderlas hacia el resto de la región. Dematteis, G. (1995) y Camagni, R. $(1992,2005)$ interpretan que desde las ciudades organizan las relaciones a través de las cuales se intercambian tecnología, servicios, innovación, información, conocimiento, etc., y en este mismo proceso de interacción se generan ventajas, que añadidas a las producidas en el interior de las empresas, inciden en el crecimiento económico (Boix, R., 2003).

De esta manera, el papel de las ciudades se incrementa como nexo de unión con el mercado internacional (Jordá, R. y Ruíz,F., 2009a, 2009b), pero no puede olvidarse que la dificultad para difundir conocimientos obedece sobre todo a la capacidad de acumulación por parte de la empresa y va a depender de lo que se ha denominado capacidad de asimilación, como ya se ha explicado antes.

En este proceso de innovación complejo y abierto es necesario que la empresa contemple de forma integral la postura tecnológica (Jordá, R. y González, R., 2009) que va adoptar; el tipo de innovación que pretende desarrollar; cuáles van a ser sus fuentes de tecnología, el esfuerzo innovador que deben realizar (valor económico que destinará a innovación), etc. En consecuencia, debe de formalizar de manera tangible la toma de decisiones relativas a la visión y misión de la tecnología para la empresa. Y esto se consigue con el diseño e implantación de una estrategia tecnológica que, a su vez, debe respaldar la estrategia competitiva diseñada por la empresa y contribuir a que ésta se cumpla.

En base a estas premisas, los objetivos de este artículo son: 1.- Reconocer las empresas innovadoras andaluzas que siguen una estrategia tecnológica como instrumento que marca los objetivos, directrices y pautas a seguir en relación a los aspectos tecnológicos. 2.- Estimar el tipo de conocimiento tecnológico que se intercambia en el tejido empresarial andaluz y con el exterior, su origen, destino sectorial y territorial; 3.Identificar los tipos de empresas con relaciones tecnológicas en función de su trayectoria en actividades de innovación, dotación de recursos tangibles e intangibles, así como las características de sus proveedores y clientes tecnológicos.

\footnotetext{
3 Siguiendo las aportaciones de Cano, G. $(2007,2008)$ y los umbrales establecidos por la Consejería de Obras Públicas y Transportes (2006), se han catalogado los núcleos de población andaluces en tres niveles: : i) uno superior, formado por un conjunto de grandes ciudades (doce de más de cien mil habitantes) que corresponden fundamentalmente a las principales Áreas Metropolitanas y capitales de provincia; ii) un nivel medio formado por un conjunto numeroso de ciudades medias (entre $10.000 \mathrm{y}$ 100.000 habitantes) que se localiza esencialmente a lo largo de la costa mediterránea y en el eje económico del subbético cordobés-jienense (surco intrabético); y iii) el nivel inferior corresponde al resto de ciudades menores de 10.000 habitantes, situadas en zonas de montaña y áreas rurales.
}

ISSN: 0212-8594 ISSN-e: 2340-2776 № DOI: http://dx.doi.org/10.12795/rea.2012.i29.06 REA 29 (2012):127-157 
A la hora de realizar este estudio, la principal dificultad que existe es la no existencia de fuentes de información oficiales adecuadas que proporcionen los datos necesarios para analizar las relaciones tecnológicas definidas a través de la estrategia tecnológica. Por ello, a fin de obtener los datos primarios se realiza un amplio proceso de encuestación entre 2011 y 2012 en el marco del proyecto de I+D+i "Estrategia de innovación empresarial: comportamientos territoriales" cuyo cuestionario incluía preguntas relativas a los agentes que intervienen en el proceso de transferencia tecnológica. Por un lado, se pregunta acerca de las características de la empresa innovadora andaluza: sus rasgos estructurales, dotación de recursos tangibles e intangibles, características de las actividades de innovación y aspectos de la estrategia tecnológica. $Y$ un segundo bloque que recoge las variables necesarias sobre el tipo y modalidad de relaciones tecnológicas: proveedores y clientes tecnológicos, características de sus relaciones (antigüedad, dependencia e importancia) y productos intercambiados.

De esta manera, los datos utilizados en este artículo surgen de las encuestas realizadas a una muestra de firmas innovadoras de Andalucía que han sido seleccionadas, de entre las registradas en el DEIA ${ }^{4}$. De esta base de datos se obtiene una muestra representativa mediante técnica de muestreo estratificado con el criterio de afijación óptima de forma que se tienen presente la multiplicidad de características que aquellas presentan (tamaño, rama de actividad, capacidad tecnológica, localización territorial, etc.). A continuación se realiza un segundo cálculo del tamaño de la muestra escogiendo los estratos a partir del cruce de las variables sector y localización espacial, pero en este caso sólo considerando aquellos sectores significativos. De nuevo se distribuye la muestra entre las diferentes ciudades mediante afijación óptima seleccionando las que tienen más de 5 empresas innovadoras en cualquiera de los estratos de localización espacial. Se consideraron todos los municipios que presentaban 5 o más firmas innovadoras en base a un criterio puramente estadístico, pues el volumen de las firmas innovadoras de las ciudades con menos de 5 empresas es muy bajo (un 5,8\% del total de éstas). La muestra final ascendió a 263 empresas. De entre ellas se analizan en este artículo las 201 que realizan transferencia tecnológica ya sea a través de la compra o de la venta de este tipo de productos.

Con estos casos y para poder identificar la existencia de una tipología de empresas innovadoras andaluzas, se aplica el método de análisis clúster con el paquete

\footnotetext{
${ }^{4}$ El Directorio de Empresas Innovadoras de Andalucía (DEIA) ofrece información relativa a empresas que se ubican en Andalucía y que realizan actividades de innovación. Es fruto del trabajo de investigación continuo que desde 1998 realiza el Grupo de investigación "Estudios Geográficos Andaluces". El directorio está en continúo proceso de actualización y actualmente tiene registradas 1950 empresas tanto de ámbitos urbanos (ciudades medias y aglomeraciones) como de espacios rurales de todas las provincias andaluzas.
}

ISSN: 0212-8594 ISSN-e: 2340-2776 № DOI: http://dx.doi.org/10.12795/rea.2012.i29.06 REA 29 (2012):127-157 
estadístico SPSS v. 15. Esta técnica tiene por objetivo obtener grupos de sujetos de forma que, por un lado, une aquellos que pertenecen a un mismo grupo y que son muy semejantes entre sí y, por el otro, los separa de los casos diferentes que presentan un comportamiento distinto con respecto a los indicadores (variables) analizados. Pero esta técnica impone dos condiciones fundamentales sobre los datos. Primero que las variables a emplear han de ser de tipo cuantitativo, motivo por el cual aquellas que se obtuvieron en la encuestación de tipo cualitativas han sido recodificadas en numéricas. Y la segunda recomendación es que las variables sean tipificadas pues la comparación de los datos medidos en diferentes escalas no sólo será difícil de obtener, sino que además se puede incurrir en un error de medición ${ }^{5}$. Por ello, antes de realizar los cálculos se debe tipificar los datos de tal manera que todas las variables manejadas en el análisis clúster tienen la misma escala (media 0 y desviación típica 1 ).

Para este estudio se ha aplicado un procedimiento mixto de análisis clúster (Elías y César, 2007) ampliamente validado y aplicado (Jordá y Ruiz, 2009a; Jordá y González, 2009; Lucendo, 2007, 2009; Lucendo y González, 2012; González Relaño, 2012). Éste combina el análisis de conglomerados jerárquicos para obtener el número inicial de grupos de empresas y el análisis de $\mathrm{k}$ Medias (procedimiento clúster no jerárquico) con el que se construyen los clústeres e identifican las características de cada una de las clases.

\section{MOTIVOS Y FORMULACIÓN DE LA ESTRATEGIA TECNOLÓGICA (ET).}

La forma y contenido de las relaciones tecnológicas está estrechamente ligada al mecanismo que la empresa seleccione para acceder al conocimiento. Como ya se ha indicado en líneas anteriores, el establecimiento de relaciones tecnológicas está condicionado por la capacidad de aprendizaje, la experiencia previa y el entorno de la empresa. Y por supuesto está directamente relacionado con la estrategia definida por la empresa (Jordá, R. y González, R., 2009; Fernandez de Lucio, I. et.al., 2008) y que consiste en las diferentes actividades de innovación y las combinaciones entre ellas que se producen en el seno de la firmas (Fernández, E., 2005; Vega-Jurado, J. et al., 2009b).

Sin embargo, la tecnología puede tener diferente papel según los rasgos de la empresa o según su propia decisión. Ya que a pesar de que la tecnología es un elemento facilitador de oportunidades en las empresas competitivas y es el resultado del conocimiento científico y empírico acumulado por otros y/o por la propia empresa,

\footnotetext{
${ }^{5}$ No todas las variables originales tienen el mismo peso en el resultado final. En general, las variables con una gran dispersión (valores grandes de sus desviaciones típicas) tienen más impacto en la formación de los grupos pues ésta depende de la medida de similitud empleada para identificar los individuos afines (Sánchez ,A. y Hernández, E., 2006).
}

ISSN: 0212-8594 ISSN-e: 2340-2776 № DOI: http://dx.doi.org/10.12795/rea.2012.i29.06 REA 29 (2012):127-157 
incorporado en máquinas o sistemas productivos y desarrollado por los recursos humanos de las firmas, no todas las empresas innovadoras andaluzas al aplicar el conocimiento científico posicionan la tecnología como un fin que forma parte del propio producto innovador (pueden acometer innovaciones organizacionales, mercadotecnia, etc.). Cualquiera que sea el rol o función que desempeña, ninguna empresa puede definir una estrategia corporativa realmente competitiva si no considera el estado del arte de la tecnología y los últimos avances al respecto.

Así que un mecanismo para poder identificar las EIA que sitúan la tecnología como recurso clave para la innovación es a través del desarrollo de una estrategia tecnológica. Ésta debe estar integrada con la estrategia competitiva global y entre ambas deben definir aspectos clave o elementos básicos tales como la orientación tecnológica (inversión en I+D elevada y ser proactivo en la adquisición de tecnología externa); la utilización de nuevas tecnologías; y, la posibilidad de desarrollar nuevos productos que incorporen la tecnología como fuente de ventaja competitiva. Además, la formulación de la estrategia y su carácter estratégico debe dirigirse a organizar los recursos disponibles, tanto humanos como técnicos y económicos, con el objetivo de aumentar la creación de nuevos conocimientos o mejorar los existentes de manera que se puedan identificar las necesidades y oportunidades tecnológicas y así planificar, diseñar e implantar soluciones tecnológicas (Pavón J. e Hidalgo, A., 1997; Hidalgo, A. et.al, 1988) siempre con el fin de alcanzar la ventaja competitiva.

Con la finalidad de identificar las empresas innovadoras andaluzas que tienen establecida una esta estrategia tecnológica se incorporó en el cuestionario una serie de preguntas de valoración con escala likert (1 a 5) en el apartado de Estrategia referentes a los motivos que llevan a adoptarlas y los aspectos que contribuyen a su formulación siguiendo a Escorza, P. y Valls, J., (2000, 2003) y Porter, M. (1990, 2009a) En relación a las razones que llevan a implantar una ET se distinguían: 1. motivos externos a la empresa: rivalidad competitiva entre empresas (mantener la cuota de mercado según ámbitos geográficos y la aparición de nuevos competidores); poder de negociación de los clientes; poder de negociación de los proveedores; amenaza de productos sustitutivos; amenaza de nuevos participantes; y, la administración pública. 2. motivos internos: producir con nuevos procesos; extender la gama de productos; reducir los costes de producción; mejorar la calidad de los productos; mejorar la flexibilidad de la producción; mejorar condiciones de trabajo.; reducir daños medioambientales.

Y acerca de los aspectos que contribuyen a cómo formular la estrategia tecnológica se solicitaba la valoración de los siguientes ítems: posicionamiento competitivo a alcanzar por la empresa en las tecnologías relevantes; misión de la tecnología y de la innovación en la empresa; definición y planificación de las líneas prioritarias de I+D; identificación de las tecnologías relevantes para la empresa; ciclo de vida de las tecnologías; análisis de desarrollo interno frente a la adquisición externa; identificación de las fuentes

ISSN: 0212-8594 ISSN-e: 2340-2776 № DOI: http://dx.doi.org/10.12795/rea.2012.i29.06 REA 29 (2012):127-157 
externas para las tecnologías relevantes; y, evaluación de tecnologías alternativas a las propias de la empresa.

Durante el proceso de encuestación se detectó que en algunas ocasiones la empresa (la persona entrevistada) tenía conocimiento de la posición que debían adoptar la empresa frente a la tecnología y cuales son las principales vías para alcanzarlas, cómo introducirlas en los procesos, etc. pero no identificaba de manera explícita un documento físico que relacionara estas acciones con la estrategia tecnológica de la firma. Por ello, para este estudio y en base a las respuestas del cuestionario se considera que las empresas siguen una estrategia tecnológica si cumplen los siguientes requisitos: a) valorar como importante o muy importante (entre 4 y 5 de la escala likert) al menos cuatro de los ítems referidos en los aspectos que llevaban a la formulación de la ET.; y b) destinar más de un 7\% de su facturación a actividades de innovación y desarrollo tecnológico siguiendo el criterio ya adoptado en investigaciones realizadas por Jordá, R. y Ruíz, F. (2010) y lo aportado por Escorsa, P. y Valls, J. (2003) que vinculaban también la estrategia tecnológica con la inversión en tecnología. De este modo, se han identificado que el $49 \%$ de las EIA tienen definidos los objetivos, la posición y el papel que la tecnología debe desarrollar en su empresa.

En función de estos criterios, las empresas innovadoras andaluzas que siguen una estrategia tecnológica se ubican en áreas metropolitanas (81\%) de Sevilla, Málaga y Granada que es donde se ubican los Parques Tecnológicos más importantes. Pertenecen a de base científica como los servicios avanzados (47.7\%) e industrias de química y electrónica (16\%). Además, la internacionalización es también un rasgo común entre ellas que implica también un mayor esfuerzo en inversión en tecnología. De media, la empresa que participa de los mercados globales y con unas directrices definidas en tecnología destinan el 9.5\% de su facturación a estas actividades, destacando sobremanera el esfuerzo de los servicios de software, laboratorios de las aglomeraciones urbanas cuya aportación asciende hasta el 13.9\%.

En relación a causas que llevan a implantar la ET se observa que el $76 \%$ de las empresas han considerado como motivo principal mejorar la calidad de sus productos (valoración 4.4/5, la más elevada). Los únicos que no lo consideran son los servicios dominados por los proveedores y los servicios de base científica, en ambos casos de espacios rurales. Predominan las causas internas sobre las externas a la hora de definir la estrategia. Según la encuesta extender la gama de productos (para el $60 \%$ de las firmas) y reducir costes (68\%) es un motivo importante $(4.2 / 5$ para ambos casos) que se pretende alcanzar a través del uso más eficiente de la tecnología.

Por otro lado, reducir los daños medioambientales es el menos considerado, pero quizá se encuentra la justificación en que hay un elevado número de firmas de servicios cuyo impacto ambiental apenas si es apreciable. Además, mejorar la flexibilidad de la producción y producir con nuevos procesos han sido considerados por la mitad de las empresas ( $49.6 \%$ y $54.2 \%$, respectivamente) pero con una apreciación media-alta. De ello se puede deducir que la definición del papel de la tecnología está 
vinculada y orientada a las innovaciones de producto (y menos a las de proceso) ya que además, como se indica, la mejora de la calidad es la motivación principal.

Acerca de los motivos externos, ninguno de ellos tiene una consideración importante a la hora de definir la estrategia tecnológica. La orientación hacia los clientes y su poder de negociación lo estiman el $56 \%$ de las empresas (con 3.9/5 de valoración media) y los competidores no son considerados en este sentido (tan sólo por el 31.3\% de las EIA). Por tanto, en relación a la influencia de agentes externos sobre el papel de la tecnología en el tejido innovador andaluz, se observa cómo prácticamente se atiende a los clientes, sin que proveedores, competidores, ni la amenaza de la aparición de productos sustitutivos puedan ejercer efecto directo en el desencadenante de una estrategia que defina el papel de la tecnología.

Por otra, para identificar las líneas de actuación y los objetivos marcados en lo referente a la tecnología, el análisis de los motivos se debe completar con los aspectos de la formulación de la ET. Los resultados del proceso de encuestación ponen de manifiesto que: a) alcanzar un posicionamiento competitivo en las tecnologías relevantes, lo han señalado de alguna manera el $62 \%$ de las firmas como objetivo prioritario de su ET. Son las empresas de base científica de grandes ciudades $(17.9 \%$ servicios y $9.5 \%$ industrias); b) el $66.2 \%$ de las EIA centran sus acciones estratégicas en la identificación de tecnologías relevantes en el futuro. Consideran importante este aspecto las firmas de servicios e industrias de base científica $(18.6 \%$ y $8.7 \%$, respectivamente), así como las industrias a gran escala, todas ellas de aglomeraciones urbanas y; c) como aspectos menos considerados está la posibilidad de desarrollar tecnología interna frente a la adquisición externa (3.7 de valoración media por el 51\% de las EIA). Ello explica la predisposición a captar conocimiento tecnológico externo a la empresa y establecer relaciones comerciales tecnológicas como mecanismo prioritario del desarrollo tecnológico de las EIA.

\section{RELACIONES TECNOLÓGICAS: CARACTERÍSTICAS DE LOS PRODUCTOS INTERCAMBIADOS.}

Tradicionalmente, las empresas comercializaban la tecnología de manera indirecta incorporada en sus productos y servicios (Fernández Sánchez, 2005). Sin embargo, recientemente se asiste a un crecimiento sin precedentes de diversos productos y mecanismos para el intercambio de tecnología o servicios tecnológicos (COTEC, 2001, 2010). A continuación se estudia el papel del tejido innovador andaluz en la transferencia tecnológica analizando, por un lado la venta $y$, de otro, la compra atendiendo al tipo de producto intercambiado ${ }^{6}$, así como su destino y origen

\footnotetext{
${ }^{6}$ Licencia de patentes; modelos de utilidad; know how; plantas llave en mano; asistencia técnica; bienes de equipo; software; marcas; nombres comerciales; $y$, dibujos y modelos industriales.
}

ISSN: 0212-8594 ISSN-e: 2340-2776 № DOI: http://dx.doi.org/10.12795/rea.2012.i29.06 REA 29 (2012):127-157 
geográfico $^{7}$. Ello facilita el poder valorar la dependencia tecnológica de las empresas innovadoras de Andalucía que se incrementa cuanto mayor parte de tecnología proceda del exterior y menos se exporte y se acentúa según sea más necesaria para el comprador y más concentrada geográficamente esté la fuente que abastece.

\subsection{VENTA DE TECNOLOGÍA.}

Según los datos de las encuestas, tan sólo un $28 \%$ de las EIA realizan venta de tecnología y son las empresas de servicios avanzados de las grandes ciudades. Éstas últimas suponen casi la mitad de todas ellas (43.8\%) siguiéndole de lejos las industrias de base científica de las aglomeraciones (16.4\%). Si bien, estos datos están referidos al número de empresas, es cierto que las firmas pueden transferir más de un producto tecnológico.

Sobre el total de productos comercializados por las EIA, destacan el Know how (34.8\%) y software (18.7\%). Entre ambos productos existe una diferencia sustancial y se trata del alcance geográfico de la misma. Mientras que el primer caso, el mercado principal es el nacional (más del 50\%), seguido del regional (18\%) y destaca también el europeo y del resto del mundo; el software comercializado se queda en gran medida en Andalucía, como sucede también con el resto de tecnologías transferidas a excepción de las patentes, pero éstas sólo suponen el $4.6 \%$ de la tecnología vendida. De esta manera se pone de manifiesto que las empresas innovadoras comienzan a superar las fronteras andaluzas en cuanto a la venta de productos tecnológicos se refiere, ya que el mercado regional supone el 54\%, España el 31\% y el extranjero apenas el $15 \%$.

Profundizando en la venta de Know how como producto principal se detecta que son 12.9\% de EIA las que la llevan a cabo esta transacción. Son firmas grandes en facturación, todas ellas internacionalizadas, con participación de capital nacional y extranjero de las aglomeraciones de Sevilla y Algeciras. Son empresas muy conocidas por ser referentes de su sector (agroalimentación, telecomunicaciones, químico) habituadas a tener vínculos continuos y frecuentes con otras empresas no andaluzas (a través de la comercialización de productos y realizar cooperación internacional en I+D) lo que les facilita la entrada en el mercado tecnológico. Sin embargo, el comportamiento contrario tiene las empresas que venden software, ya que tan sólo unas pocas están internacionalizadas. Trabajan para empresas próximas geográficamente y lo que comercializan fuera de Andalucía, queda en Madrid.

Al completar este análisis con el sector de actividad de la empresa que vende, se pone de relieve que el Know how no sigue ningún patrón sectorial, sino que se comercializa por casi todos los sectores. Este hecho encuentra su justificación en las características del producto ya que la venta de Know how consiste en la transferencia de

\footnotetext{
7 Andalucía, España, Europa y Resto del Mundo.
} 
conocimientos técnicos, modelos, fórmulas, datos, documentación técnica, instrucciones, etc., específicos a cada sector y necesario para todos ellos. En el resto de productos, salvo en los bienes de equipo que venden las industrias, son los servicios de base científica los que dominan este mercado.

Así que los servicios de base científica destacan en las ventas tecnológicas desde el punto de vista sectorial. El $44 \%$ de sus firmas comercializan tecnología, salvo el $11 \%$ que se localizan en ciudades medias de Jaén, el resto se ubican en Málaga (31\%), Sevilla (17\%) Granada y Cádiz (14\%, en cada caso). Por regla general dedican una parte muy importante de su facturación a la investigación y desarrollo (el $60 \%$ de ellas destinan más de un $10 \%$ de ingresos a estas actividades), aunque únicamente el $6 \%$ de ellas acometen investigación básica. Realizan desarrollo tecnológico (57\%) e investigación aplicada (40\%) lo que ha llevado a registrar 46 software y Know how, así como 43 patentes y modelos de utilidad. Sus transacciones las formalizan con firmas del mismo grupo de actividades tales como servicios avanzados, consultorías, servicios informáticos y otras como la administración pública. De tal manera que el $68.5 \%$ de sus ventas tienen destino final Andalucía, 20\% España y un $8.5 \%$ a Europa. El $80 \%$ de estas EIA tienen acuerdos de cooperación en I+D y el $63 \%$ también adquieren tecnología.

Además, las industrias de base científica son otro grupo que destaca en la venta de tecnología. Estas son de las aglomeraciones de Sevilla y Granada, con la excepción de dos firmas en ciudades medias de Córdoba y Jaén, todas ellas con departamento de I+D, donde llevan a cabo actividades de investigación aplicada y desarrollo. Entre todas ellas han registrado 77 patentes, modelos de utilidad y/o modelos de desarrollo, así como 9 software. Vende su tecnología a empresas de telecomunicaciones, alimentación y aeronáutica como clientes principales (35\% a firmas andaluzas, $28 \%$ nacional y otro $28 \%$ al resto del mundo como Brasil o Chile), a las que transmiten Know how (64.2\%) y asistencia técnica (42.8\%). Estas EIA además de vender compran tecnología (71.4\%) y casi todas tienen establecidos varios acuerdos de cooperación con otras empresas e instituciones para desarrollar tecnología.

Por último se confirma el escaso papel de los ámbitos rurales y se aprecia cómo las ciudades medias comienzan a vender Know how $\mathrm{y}$, de manera poco significativa, asistencia técnica y marcas a otras empresas.

\subsection{COMPRA DE TECNOLOGÍA.}

En lo que se refiere a la adquisición de productos tecnológicos, además de ser muy superior a la venta en cuanto al número de empresas que la llevan a cabo (73.7\%), tiene rasgos muy diferentes en relación a la venta. En la entrada de tecnología destaca sobremanera los bienes de equipo (58\%), seguido de lejos del software (17\%). Pero en ambos casos, como para el resto de insumos, la procedencia es externa a Andalucía. Las actividades de base científica siguen siendo los sectores relevantes en las transacciones tecnológicas, pero aparecen otros como manufacturas de producción a

ISSN: 0212-8594 ISSN-e: 2340-2776 № DOI: http://dx.doi.org/10.12795/rea.2012.i29.06 REA 29 (2012):127-157 
gran escala de las aglomeraciones urbanas y de ciudades medias como demandantes de estos productos. Sobre el total del sector se comprueba que salvo los servicios de producción a gran escala (que por su naturaleza no necesitan estos inputs), todas las actividades incorporan a sus procesos productivos tecnología externa a la empresa. En este caso la localización de la firma innovadora no influye ni condiciona la demanda de productos tecnológicos.

En el análisis de los datos según los productos y el origen de los mismos, el $40 \%$ de los productos son extranjeros. La mitad del software, de las plantas llave en mano y de los bienes de equipo proceden del exterior de Andalucía. Significativo es el caso del software que a pesar de ser un importante producto tecnológico que se genera en Andalucía, sin embargo, la mitad del que se compra se hace en Estados Unidos. Las características del software son diferenciadas y se adapta exclusivamente a los requerimientos de las empresas compradoras, por lo se distingue una parte de empresas que no estando internacionalizadas requieren software a empresas que lo generan en un entorno muy próximo, mientras que hay otras firmas que por pertenecer a un grupo de empresas internacional, por tener capital foráneo, por cooperar internacionalmente acceden a empresas más alejadas diseñando éstos últimos programas informáticos diferenciados y específicos a la demanda de su empresa.

Pero este hecho, debe ser entendido como una manera de difusión de la innovación, puesto que una vez se incorpora la tecnología externa a los procesos productivos de las firmas andaluzas, el producto y el conocimiento asociado a él puede ser modificado y adoptado por firmas competidoras/colaboradoras e incluso clientes a través, en muchos casos, de ingeniería inversa, de acciones formativas a los empleados de la empresa o mediante las relaciones formales e informales entre personal cualificado. Además se ha detectado (al analizar los datos atendiendo a total de productos adquiridos) que varias empresas adquieren software de distinto origen y que éste es a la vez la "materia prima" para la generación de otros software que venden a las empresas andaluzas próximas. Este hecho sucede en las aglomeraciones urbanas (que compran el $83 \%$ del software) entre las firmas de servicios de base científica.

Por otro lado, destaca el caso de los bienes de equipo por ser el producto más adquirido. Predomina su origen externo ya que sólo un $25 \%$ se genera en Andalucía y el resto proceden de Francia, Alemania, Italia y otra parte importante de China, Japón y Estados Unidos cuyo compradores son sectores de agroalimentación y automóviles.

Ante esta situación cabe cuestionarse porqué las empresas innovadoras andaluzas compran fundamentalmente bienes de equipo. Algunos autores apuntan al marcado dinamismo tecnológico de este producto que generalmente está influido por los diversos procesos productivos de numerosos e indistintos sectores de actividad. Ello provoca una aceleración de la velocidad del cambio y desarrollo tecnológico obligando a las empresas a estar alerta a estos cambios para poder responder a las necesidades

ISSN: 0212-8594 ISSN-e: 2340-2776 № DOI: http://dx.doi.org/10.12795/rea.2012.i29.06 REA 29 (2012):127-157 
del mercado global. Y éste dinamismo se refleja también en la necesidad de los espacios rurales y ciudades medias de adquirir bienes de equipo para poder seguir siendo competitivas. El $21 \%$ de las empresas rurales y el $16 \%$ de las ciudades medias que compran bienes de equipo lo hacen en Andalucía, el resto son de fuera.

En definitiva la compraventa de tecnología está marcada por el intercambio de dos productos principalmente. Se compra bienes de equipo extranjeros y se vende Know how en Andalucía. El software es otro producto principal que circula tanto por los canales de entrada como de salida de tecnología pero siempre permanece en el entorno regional. Ahora bien, no todas las empresas tienen el mismo comportamiento ya que de este análisis se intuye la existencia de varios tipos de empresas que en función de sus rasgos estructurales, sus capacidades y la definición de una estrategia tecnológica, se posicionan de manera diferente en los mercados tecnológicos. Se pretende a continuación identificar la existencia de una tipología de empresa, sus rasgos definitorios, así como las características comunes a entre ellas.

\section{TIPOLOGÍA DE EMPRESAS INNOVADORAS ANDALUZAS SEGÚN RELACIONES TECNOLÓGICAS.}

\subsection{VARIABLES UTILIZADAS Y ANÁLISIS DE LOS DATOS.}

Para la identificación de los diferentes tipos de empresas innovadoras atendiendo su estrategia tecnológica que define o vincula las relaciones de compra y/o venta de tecnología, se ha realizado un análisis multivariante clúster con el método mixto descrito en el punto tres. Este unirá las empresas con rasgos similares y las diferenciará del resto con otras características en función de las relaciones tecnológicas que tenga, el papel que la tecnología ostente en el seno de la empresa en base a una estrategia diseñada y a las capacidades internas requeridas para la óptima integración del conocimiento externo captado y el desarrollado.

En base a los objetivos de este artículo y sobre las respuestas del cuestionario se han introducido para el análisis clúster tres bloques de variables: dos bloques que engloban las variables relacionadas con la empresa proveedora por un lado y las que tienen que ver con los clientes de tecnología de las EIA por otro. Para ambos casos se incluyen los datos acerca de: localización según grandes regiones (Andalucía, España, Europa y Resto del Mundo); sector según clasificación de Pavitt y Miozzo y Soete; duración del vínculo (medido en años) y tipo de producto adquirido.

Y el tercer bloque incluye las variables relacionadas con los rasgos de la empresa innovadora de Andalucía que su vez distingue entre:

ISSN: 0212-8594 ISSN-e: 2340-2776 № DOI: http://dx.doi.org/10.12795/rea.2012.i29.06 REA 29 (2012):127-157 
a) Características estructurales: localización (aglomeración, ciudad media o ámbito rural), sector de actividad; facturación; haber realizado cambios estratégicos en la empresa (SI, NO).

b) Actividades de innovación: investigación básica, investigación aplicada, desarrollo tecnológico, adaptación e ingeniería; esfuerzo en actividades de innovación (\% facturación destinado a innovación); tipo de tecnología que utiliza la empresa (propia, adquirida); resultados tecnológicos registrados.

c) Recursos internos (escala likert 1 a 5 según valoración del entrevistado) pues parte de las capacidades para generar, transformar y adoptar la tecnología viene dada por: recursos humanos; recursos organizacionales; recursos físicos; localización geográfica.

d) Formulación de una estrategia tecnológica de la firma (escala likert 1 a 5 según valoración del entrevistado). De entre todos los aspectos se han introducido para el análisis aquellos más significativos, detectados mediante el análisis realizado en el apartado 3: identificación de las tecnologías relevantes para la empresa en el futuro; análisis de desarrollo interno frente a adquisición externa; identificación de fuentes externas para las tecnologías relevantes; evaluación de tecnologías alternativas a las propia de la empresa; posicionamiento competitivo a alcanzar por la empresa en las tecnologías relevantes.

Para no incurrir en un error de medición y como requisito previo para realizar correctamente el análisis clúster se tipificaron las variables con el método de "Puntuaciones $Z$ ". De esta manera todas las variables tienen la misma escala, media 0 y desviación típica 1. Siguiendo lo explicado en metodología (punto 2), se aplica un procedimiento mixto. El primero (conglomerado jerárquico) se caracteriza por el desarrollo de una estructura de grupos a partir de la distancia entre individuos que gráficamente se representa en forma de árbol de clasificación (dendograma) de cuyo estudio se obtiene la información necesaria acerca de cuál es el número de clústeres que pueden formarse. Se detectaron entre 6 y 8 conglomerados.

Pero este método no ofrece la tabla con la partición del conjunto de empresas por cada clúster de pertenencia y la caracterización de cada una de las clases (con los valores promedio de los conglomerados formados en torno a los centroides), según las variables empleadas para la agrupación. Para obtener esta información se aplica entonces el análisis de k Medias como método no-jerárquicos de clasificación de los individuos en $k$ clúster, donde $k$ es el número de grupos que se especifica a priori mediante el análisis de conglomerados jerárquicos. Se realizaron las pruebas pertinentes a través del $K$ medias y se obtuvieron los siguientes resultados: 
Cuadro 1. Número de casos en cada conglomerado según relaciones de compraventa de tecnología.

\begin{tabular}{|l|l|l|l|}
\hline \multicolumn{1}{|c|}{ Clúster } & \multicolumn{1}{|c|}{6 Conglomerados } & \multicolumn{1}{|c|}{7 Conglomerados } & \multicolumn{1}{|c|}{$\mathbf{8}$ Conglomerados } \\
\hline 1 & 10 & 20 & 2 \\
\hline 2 & 74 & 3 & 3 \\
\hline 3 & 70 & 98 & 9 \\
\hline 4 & 40 & 9 & 60 \\
\hline 5 & 1 & 69 & 76 \\
\hline 6 & 6 & 1 & 8 \\
\hline 7 & & 1 & 2 \\
\hline 8 & & & 41 \\
\hline Total Casos & 201 & 201 & 201 \\
\hline
\end{tabular}

Fuente: Elaboración propia a partir del análisis clúster realizado con SPSS v.15 con los datos de la encuesta.

Las soluciones de 7 y 8 conglomerados se desestimaron. En el caso de 7 grupos porque un conglomerado aglutinaba el $48,7 \%$ de las empresas que compran y/o venden tecnología, y el resto de firmas quedan clasificadas en dos grupos (que suman el $44,2 \%$ de EIA). Ello hace que se pierda las características diferenciadoras entre las firmas y no pueda analizarse bien los rasgos vinculados a las relaciones tecnológicas. El caso de 8 conglomerados tampoco se considera óptimo pues aunque no se detecta un grupo especialmente grande (el mayor tiene el $37,8 \%$ de firmas) y se dan tres grupos con pocos individuos. Así que una clasificación de empresas en base a estas relaciones se sustenta sobre 6 conglomerados.

Para clasificarlos estos seis grupos se atiende como criterio principal a la compra de tecnología (según lo analizado en el punto 4) puesto que, como se ha explicado, son pocas las firmas que venden tecnología ( $28 \%$, frente al $73 \%$ que los adquieren). Y así, se observan dos subgrupos ( $\mathrm{A}$ y $\mathrm{B}$ ) en los que el origen geográfico de los productos es la clave diferenciadora. En el primer caso (para dos conglomerados) predomina la compra de tecnología a escala regional, mientras que en el segundo (con los otros 4 conglomerados) presenta relaciones externas. El umbral para marcar esta diferencia entre relaciones tecnológicas internas y externas se ha establecido en el valor de compra superior al $30 \%$ fuera de Andalucía, puesto que éste es el porcentaje medio para los 6 clúster identificados.

\subsection{GRUPO A. RELACIONES INTERNAS DE COMPRA DE TECNOLOGÍA.}

Clúster A.1. Lo forman el 5\% de las EIA con relaciones tecnológicas. Se trata de un grupo de empresas poco internacionalizadas (30\%), de las aglomeraciones (80\%) de Sevilla $(50 \%)$ y Cádiz $(25 \%)$ y algunas en ciudades medias de Jaén, que acometen actividades de desarrollo tecnológico e ingeniería ( $70 \%$ y $40 \%$, respectivamente) para la producción de productos nuevos para el mercado (50\%) y mejorados. Destaca por destinar a innovación más recursos económicos que otros grupos $(12,8 \%$ de una 
facturación media de 13 millones de euros) y han registrado como mínimo 2 software como productos tecnológicos propios en cada empresa. Son los que mayor importancia han dado al capital humano como recurso esencial para la competitividad de sus firmas, seguidos de los recursos físicos (maquinaria, equipos y otras herramientas).

Cuadro 2: Centros de conglomerados finales.

\begin{tabular}{|c|c|c|c|c|c|c|c|}
\hline & & \multicolumn{6}{|c|}{ Conglomerado } \\
\hline & VARIABLE & A.1 & B.1 & B.2 & A.2 & B. 3 & B.4 \\
\hline \multirow{6}{*}{$\begin{array}{l}\text { ơ } \\
\text { 몀 } \\
\text { ơ } \\
\text { ơ }\end{array}$} & DURACION_VINCULO &,- 51701 &,- 02970 & 29535 &,- 38152 & 1,88540 & 01147 \\
\hline & 'GASTO/FACTURACION & ,20564 & 13674 &,- 11773 &,- 10886 & ,81014 &,- 06495 \\
\hline & TEC.PAVITT_RELAC & 69115 &,- 07230 &,- 32516 & ,65503 &,- 87816 &,- 68719 \\
\hline & TEC.TIPO INTERCAMBIO 2DIG &,- 26253 & 19959 & ,19522 &,- 57198 & ,42333 &,- 55903 \\
\hline & TEC.ANTIGUEDAD_RELACION) &,- 49886 & 07113 & 17496 &,- 38140 & 2,18480 & 09148 \\
\hline & TEC.IMPORTANCIA_RELAC & ,20564 & 13674 &,- 11773 &,- 10886 & ,81014 &,- 06495 \\
\hline \multirow{14}{*}{ 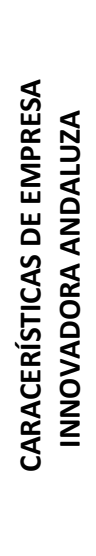 } & PRODUCTO1_TIPO &,- 00686 & ,09874 & 12448 &,- 35163 & ,22298 &,- 35163 \\
\hline & ID_BASIC &,- 07369 &,- 29426 & 05586 & 37971 & 2,64669 & 12782 \\
\hline & ID_APLIC &,- 36639 &,- 02725 &,- 13129 & 25074 & 1,27928 & ,59359 \\
\hline & ID_DES &, 54866 &,- 01803 &,- 20018 & 19584 &,- 86262 & ,48146 \\
\hline & ID_ADAPT &,- 08077 &,- 00099 &,- 20124 & ,28819 & 1,39505 & ,34089 \\
\hline & ING_1 & ,28274 & ,08319 &,- 03689 &,- 22068 & 1,62522 & ,13358 \\
\hline & INTERNACIONALIZADO &,- 76255 & 08646 & 08077 &,- 18277 & ,71326 & ,36187 \\
\hline & INVERSION ECNOLOGIA & ,73067 &,- 12526 &,- 28661 &, 53010 &,- 33184 & ,19219 \\
\hline & 3 LOCALIZ & ,24775 & 06258 &,- 39680 & ,41486 & ,58196 & ,58196 \\
\hline & PAVITT & 1,02513 &,- 11112 &,- 42941 & ,72457 &, 84426 &,- 29946 \\
\hline & FACTURACION) &,- 24152 & ,13456 & 03321 &,- 22701 &,- 21748 &,- 09477 \\
\hline & SOFTWARE+KNOW HOW & ,05400 &,- 08863 &,- 24472 & 42740 & 4,63436 & ,23655 \\
\hline & BEQUIPO+PLANTAS LLAVE MANO & ,79922 & 12729 &,- 19968 &,- 23169 & 4,50453 & ,22151 \\
\hline & PATENTES+MUTILIDAD+MINDUSTRIA &,- 32054 &,- 03870 &,- 14528 & ,20383 & 5,53659 & ,42479 \\
\hline \multirow{15}{*}{ 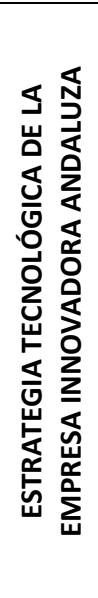 } & Cambios S/N &,- 04986 &,- 22853 & 16338 & 21670 &,- 68961 &,- 33420 \\
\hline & RRHH_SUBTOTAL & 1,06754 &,- 00039 &,- 66960 & 90031 & ,54899 &,- 05598 \\
\hline & RROO_SUBTOTAL &,- 90731 &,- 01355 & ,41322 &,- 56879 &,- 67250 & ,76245 \\
\hline & RRFF_SUBTOTAL &,- 62508 & ,04362 & ,49932 &,- 70524 &,- 11494 &,- 60078 \\
\hline & TECNOLOGIA_ADQUIRD & $-1,0225$ & ,26500 & 24874 &,- 70280 & ,41622 & 14978 \\
\hline & TECNOLOGIA_PROPIA &,- 22291 & 11621 &,- 12411 & 01174 & ,61688 & ,20522 \\
\hline & RRFFLOCALIZACION &,- 51125 & ,12405 & 12767 &,- 32924 &,- 19922 & ,06080 \\
\hline & OBJETIVO_APRENDIZAJ & ,37381 & ,15681 &,- 29173 &, 06405 & ,57205 &, 32425 \\
\hline & MOTIVOS INTERNOS &,- 30481 & ,70053 &,- 52015 &,- 54793 & ,74872 & 1,46458 \\
\hline & MOTIVOS EXTERNOS &,- 69454 & 69899 &,- 44527 &,- 46760 & 1,23192 & ,64356 \\
\hline & FORMU_TECNOLOGIAS &,- 31818 & 68430 &,- 48207 &,- 38988 & 1,02019 & 14387 \\
\hline & FORMU_ANALISIS & ,03913 & ,73631 &,- 81235 &,- 13186 & 1,45594 & 96739 \\
\hline & FORMU_FUENTES EXTERNAS &,- 10836 & ,72807 &,- 62115 &,- 31452 &,- 15687 &, 57075 \\
\hline & FORMU_ALTERNATIVAS &,- 43041 & ,77458 &,- 63428 &,- 31968 & ,45538 & 61941 \\
\hline & FORMU_POSICIONAMIEN &,- 14912 & 67111 &,- 58535 &,- 30180 & ,22672 & ,77481 \\
\hline \multirow{6}{*}{$\underset{\text { 岂 }}{\stackrel{\text { U }}{J}}$} & DURACION_VINCULO & ,17264 &,- 19258 &,- 31868 & ,24964 & 5,76781 & 3,17983 \\
\hline & GASTO/FACTURACION & 3,52730 &,- 24362 &,- 29494 &,- 12319 & ,27965 & 1,34138 \\
\hline & TEV.PAVITT_RELAC & ,41948 &,- 20041 &,- 39135 & ,96224 &,- 23184 &,- 03800 \\
\hline & TEV.TIPO INTERCAMBIO 2DIG & 1,32059 &,- 22572 &,- 54832 & ,80818 & 1,37710 & 1,36261 \\
\hline & TEV.ANTIGUD_RELACION & ,17822 &,- 19348 &,- 34922 & ,20211 & 1,15799 & 4,62306 \\
\hline & TEV.IMPORTA_RELAC & 3,35805 &,- 23853 &,- 30304 &,- 13853 & ,24732 & 1,76280 \\
\hline
\end{tabular}

Fuente: Elaboración propia a partir del análisis clúster realizado con SPSS v.15 con los datos de la encuesta 
Sin embargo, los recursos organizacionales (estructura de la empresa) no parecen tener gran relevancia y esto se pone de manifiesto incluso en su postura estratégica. Pocas firmas han acometido cambios estratégicos. De hecho, se detecta que no otorgan importancia (media 2 sobre 5 en escala likert) a los diferentes aspectos que contribuyen a la formulación de una estrategia tecnológica. Sin embargo, atendiendo al criterio adoptado sobre el valor en actividades de innovación y al ser éste tan elevado para el grupo, debe comprenderse que las empresas buscan un fin y tienen marcados implícitamente unos objetivos. Éstos tienen que ver con los aspectos meramente internos a la firma tales como reducir costes y mejorar calidad, por encima de aspectos externos como la rivalidad entre competidores o el poder de negociación con proveedores y/o clientes.

Todas las empresas de este grupo compran y venden tecnología. Adquieren Know how y material informático a firmas de servicios de base científica de Andalucía (67\%), España (22\%) y Resto del Mundo (11\%). Sus proveedores tecnológicos tienen una importancia elevada (casi la mayor de todos los grupos) para estas EIA a pesar de que son relaciones muy recientes (las más novedosas de todos los clúster).

En cuanto a la venta de tecnología, la duración del vínculo es de unos 5 años (igual que la compra). Sin embargo, en relación con el resto de grupos, estas firmas llevan en los mercados tecnológicos más tiempo que muchos otros grupos. Venden software y Know how a industrias de producción a gran escala andaluzas (80\%) y nacionales $(20 \%)$ pero aún no están capacitadas para comercializar en el extranjero.

Clúster A.2. Está compuesto por el $20 \%$ de las empresas innovadoras con relaciones tecnológicas y puede decirse que es un grupo diferenciado y distinto por ser el que aglutina a las EIA que venden tecnología: el $85 \%$ compra y el $75 \%$ vende productos tecnológicos.

Son empresas de base científica (servicios técnicos, ingeniería, ensayos y análisis, empresas dedicadas a la investigación y desarrollo experimental; programación y consultoría) con elevada aportación económica a la investigación. De media dedican por encima del $11 \%$ de su facturación a estas actividades. Se caracteriza además por englobar a las empresas que hacen investigación básica, aplicada y desarrollo. El 62\% de ellas comercializan productos nuevos para el mercado y el $25 \%$ nuevos para la empresa. Se localizan en su totalidad en las aglomeraciones urbanas: en Málaga el $32 \%$, Sevilla $30 \%$ y Granada $22 \%$ (la mitad de ellas se ubican en sus parques científicos y tecnológicos). Son pequeñas firmas en cuanto a facturación (16 millones euros) que consideran que sus capacidades esenciales se sustentan sobre la cualificación y formación del personal empleado.

La tecnología propia se valora por encima de la adquirida pero aun así no se considera especialmente relevante (tan sólo 2.8 en una escala de 5). Como sucede en el grupo 
A1, el esfuerzo económico en innovación es elevado pero no se posicionan en el mercado con una estrategia tecnológica definida ya que ninguno de sus aspectos que la formulan alcanza una valoración importante. $Y$ es el conjunto de empresas que menos consideran las motivaciones internas o externas para desarrollar este tipo de estrategia.

Dado que en su mayoría son firmas de servicios, la compra tecnológica que realizan es software específico a otras empresas de base científica de Andalucía (41\%) y extranjeras (38\%, Estados Unidos casi en su totalidad). Tanto las relaciones de compra como las de ventas son relativamente recientes dado que son empresas jóvenes, con unos 15 años de vida de media. Por otro lado, venden Know how a otras empresas de servicios de base científica de Andalucía (50\%), del resto del mundo (20\%) y de España (30\%).

\subsection{GRUPO B. RELACIONES EXTERNAS DE COMPRA DE TECNOLOGÍA.}

Clúster B.1. Suponen el $37 \%$ de las EIA con relaciones tecnológicas. Es el grupo con mayor facturación de media (80 millones de euros). Casi todas las empresas están internacionalizadas (70\%) y se concentran en las aglomeraciones (73\%) pero sin destacar ninguna en especial ya que en Málaga está el 29\%, en Cádiz el 20\%; Sevilla $16 \%$ y Granada 13\%. También se localizan algunas de estas firmas en ciudades medias de Córdoba y Sevilla. Pertenecen a las industrias de producción a gran escala (procesado y conservación de frutas y hortalizas, preparación de productos lácteos y otras de las industrias de la alimentación) con un esfuerzo económico medio-bajo en innovación destinando de media $4.9 \%$ de la facturación a estas actividades.

Son las que menos investigación básica acometen (sólo el 3\% de las empresas de este grupo) y se centran en el desarrollo y adaptación tecnológica (42\% y 34\%, respectivamente). El $40 \%$ de sus productos son nuevos para el mercado y otro $33 \%$ son mejorados. Aunque para estas empresas sus capacidades esenciales se sustentan sobre los recursos humanos, son el grupo que mayor importancia otorgan a los recursos físicos, sobre todo a la tecnología adquirida por encima de la propia. Así, consideran que identificar las tecnologías relevantes para la empresa en el futuro es el aspecto de la estrategia tecnológica más importante. Junto a éste destaca conocer las fuentes externas de tecnología y poder alcanzar un posicionamiento competitivo en base a las tecnologías. Puede afirmarse que este grupo tiene diseñada estrategia Tecnológica, cuyos motivos para implantarla son tanto internos como externos a la firma. Se detecta que la ET está definida para encontrar, comprar e incorporar tecnología del exterior que adaptan a sus procesos productivos.

ISSN: 0212-8594 ISSN-e: 2340-2776 № DOI: http://dx.doi.org/10.12795/rea.2012.i29.06 REA 29 (2012):127-157 
Mapa 1: Tipología de empresas según clúster obtenidos.

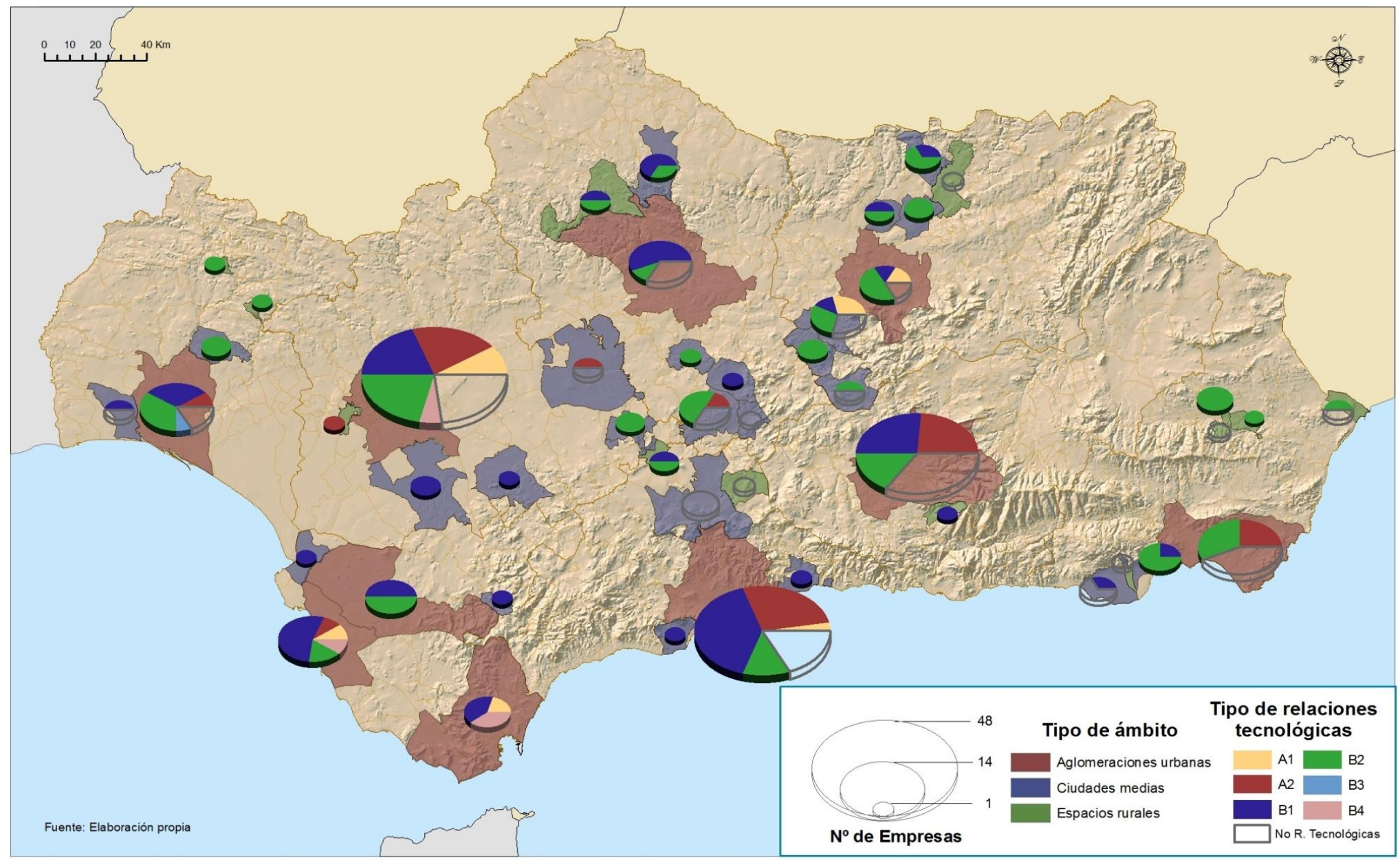

ISSN: 0212-8594 ISSN-e: 2340-2776 № DOI: http://dx.doi.org/10.12795/rea.2012.i29.06

REA 29 (2012):127-157

http://www.publius.us.es/estudios_andaluces 
Además, la totalidad de las empresas de este grupo compran tecnología y sólo una cuarta parte de ellas la venden. Adquieren bienes de equipo de empresas de base científica y a otras de producción a gran escala (47\%) del extranjero (Alemania, Holanda, Italia y Estados Unidos) con las que tiene unos vínculos antiguos (más 25 años aproximadamente). Sin embargo la adquisición de tecnología en Andalucía sólo suponen el $30 \%$ y tienen relaciones tan sólo desde hace menos de una década. La escasa venta que se acomete unas pocas firmas que transfieren el Know how y algún software específico a otras empresas del mismo sector de Andalucía.

Clúster B.2. Engloba el $35 \%$ de las empresas analizadas. Tiene algunos rasgos muy similares al caso anterior en lo que se refiere a las relaciones tecnológicas externas. Pero la diferencia principal estriba en aspectos de las características estructurales de las EIA (localización, sobre todo) y en que las firmas de éste grupo no tiene estrategia tecnológica. Es el segundo grupo en cuanto a tamaño medio de sus empresa (61 millones de euros). Son las empresas de ciudades medias (33\%) de Córdoba y Jaén (como Lucena, Martos, Mancha Real, entre otras) y espacios rurales (13\%) de Almería, Sevilla y Córdoba. Casi la totalidad de las empresas están internacionalizadas (70\%) y pocas hacen investigación y/o ingeniería, sólo una tercera parte de ellas llevan a cabo actividades de desarrollo tecnológico. Destinan poca inversión a innovación, 3.4\% de la facturación, el segundo valor más bajo. En cuanto al grado de innovación de sus productos, el $37 \%$ son nuevos para el mercado, otro $34 \%$ mejorado y el $29 \%$ restante nuevos para la empresa. Se trata de industrias de producción a gran escala como fabricación de productos metálicos, no metálicos como cerámicos, y de componentes y piezas para vehículos a motor, entre otros.

De todos los grupos detectados, son los que mayor importancia otorgan a los recursos físicos como elemento relevante de sus capacidades esenciales. Para estas empresas la tecnología adquirida tiene, como sucedía en el caso anterior, mayor relevancia que la propia, de ahí la importancia que para ellos poseen las relaciones de compra tecnológica. Sin embargo, y como se ha mencionado, estas empresas no siguen una estrategia tecnológica definida y diseñada para la adquisición de inputs tecnológicos. Ninguno de los aspectos que llevan a la formulación estratégica es considerada ni siquiera con una importancia media (no alcanza una media de 2 sobre 5).

Otra de las diferencia con el grupo B1 está en que compran bienes de equipo a empresas de proveedores especializados (maquinaria y eléctrica), mientras que el anterior lo hace a firmas de base científica del resto de España (40\%) y Unión Europea (40\%). También son menores los proveedores andaluces que en el caso anterior (20\%, frente al $30 \%$ del otro clúster). La venta de tecnología no es significativa en el conglomerado ya que sólo lo llevan a cabo cinco firmas que venden nombres comerciales a otras empresas andaluzas. Podría decirse que es el grupo que compra pero no vende tecnología.

ISSN: 0212-8594 ISSN-e: 2340-2776 № DOI: http://dx.doi.org/10.12795/rea.2012.i29.06 REA 29 (2012):127-157 
Clúster B.3. Lo compone una única empresa que el análisis clúster no la ha unido a ninguno de los otros grupos porque presenta una diferencia clara en cuanto a los resultados tecnológicos. Tiene registrado un elevado número de patentes en comparación con el resto de firmas y este hecho le lleva a tener una importante distancia al resto de casos. Para ello acomete investigación básica, desarrollo e ingeniería. Compra los royalties de las patentes a otras empresas andaluzas y vende modelos de utilidad a empresas nacionales. Su estrategia tecnológica se basa en identificar las tecnologías relevantes para la empresa en el futuro y en desarrollarlas en el seno de su empresa.

Clúster B.4. Agrupa el 3\% de las EIA estudiadas en este artículo y es el único clúster cuyo porcentaje de empresas que venden tecnología está por encima de las que compran. Es el grupo internacionalizado (el mayor valor de todos los conglomerados), con una elevada dedicación a innovación ( $7,8 \%$ de la facturación). La gran mayoría de estas EIA hacen investigación aplicada y desarrollo, obteniendo productos nuevos para el mercado. Son industrias de base científica dedicadas a la construcción aeronáutica y su maquinaria y a la fabricación de componentes electrónicos, de las aglomeraciones de Sevilla y Cádiz.

Es el clúster que mayor importancia otorga a los recursos organizacionales como parte de sus capacidades principales y el segundo grupo que menos relevancia dan a los recursos físicos (maquinarias y otros bienes). La tecnología propia prevalece a la externa y precisamente los motivos internos a la empresa tales como extender la gama de productos y producir con nuevos procesos instan a introducir una estrategia tecnológica formulada para poder alcanzar un posicionamiento competitivo en base a las tecnologías relevantes que se gestionan en la empresa. Es el grupo más vinculado a los motivos internos para desarrollar la ET. También destaca por haber patentado y registrado modelos de utilidad y modelos industriales generados en sus empresas.

Adquieren bienes de equipo a industrias a gran escala de productos metálicos y otros materiales de transporte nacionales (60\%) e internacionales (20\% europeos y otro $20 \%$ al resto del mundo), pero no compra tecnología en Andalucía. Por otra, vende Know how también a industrias aeronáuticas y vinculadas con el ejército tanto regionales (33\%), nacionales (33\%) como del resto del mundo.

\section{CONCLUSIONES.}

Del estudio del desempeño que la tecnología tiene para las empresas innovadoras andaluzas se puede afirmar que el mercado de tecnología, como mecanismo para la captación y difusión de conocimiento, es bastante frecuente entre el tejido innovador andaluz (76,7\% de las firmas de la muestra de 263$)$. Pero aún se compra tres veces más tecnología (bienes de equipo de fuera de Andalucía) de la que se vende (más de la mitad permanece en la región) debido al nivel tecnológico de las firmas y a la

ISSN: 0212-8594 ISSN-e: 2340-2776 № DOI: http://dx.doi.org/10.12795/rea.2012.i29.06 REA 29 (2012):127-157 
localización de las mismas. Predomina el uso de la tecnología convencional en ciudades medias $(55 \%)$ y espacios rurales $(64 \%)$ lo que dificulta su capacidad para la venta de estos productos.

Mientras que el $30 \%$ de la tecnología adquirida procede de Andalucía; el 56\% de las que las EIA transfieren permanece en el territorio regional. Se compra principalmente a empresas de servicios avanzados y se vende a las industrias de producción a gran escala. Además, la venta es un fenómeno relativamente reciente ya que los vínculos con los suministradores de tecnología tienen una duración media de 10 años, frente a los 3 años de antigüedad que tienen las relaciones con los clientes. A lo que hay que unir que los proveedores externos de tecnología son muy importantes en cuanto a la dependencia que se tiene de ellos (8.9 sobre una valoración de 10), mientras que los clientes no tienen esa consideración (5.9/10).

En el mercado tecnológico destacan los sectores de base científica de las aglomeraciones urbanas que se posicionan como los dinámicos. Sobresalen fundamentalmente en la transferencia y difusión de tecnología foránea en Andalucía que se complementa con una reciente introducción en los flujos de venta de Know how y software.

En esta dinámica de captar, introducir, incorporar tecnología del exterior resulta necesario realizar actividades de I+D internas en las EIA, ya sea básica, aplicada como desarrollo tecnológico y contar con una serie de recursos tangibles (aportación económica a la I+D; físicos) e intangibles (capital humano y organizacionales) para integrar con éxito los productos tecnológicos en el proceso innovador. Todo ello se complementa con la definición de unas pautas, guías y objetivos que deben ser recogidas en la estrategia tecnológica.

Así que en relación al desarrollo, implantación y seguimiento de una ET, los datos de las encuestas relativos a las distintas variables que llevan a su formulación no refleja unos valores especialmente elevados en lo referente al número de empresas que la poseen, ni en la valoración cualitativa que éstas otorgan. Las empresas con ET se concentran en espacios de aglomeración y están siempre vinculadas a actividades de alta tecnología, poniendo de manifiesto que esta práctica no está aún implantada y extendida en todo el tejido innovador andaluz. Sin embargo atendiendo al hecho que las empresas que participan de los mercados tecnológicos realizan una elevada aportación económica a actividades de innovación se puede considerar que éstas EIA si tienen una orientación, unas líneas marcadas para definir el objetivo de la inversión pero esto no queda reflejada o codificada de manera explícita en lo que formalmente se denomina estrategia tecnológica. Según los datos, en Andalucía la estrategia se diseña generalmente atendiendo exclusivamente a motivos internos a la empresa. $Y$ de atender a causas externas, los clientes son los únicos que pueden ejercer influencia y determinar los aspectos que formulan las pautas tecnológicas de la EIA.

ISSN: 0212-8594 ISSN-e: 2340-2776 № DOI: http://dx.doi.org/10.12795/rea.2012.i29.06 REA 29 (2012):127-157 
Los resultados del análisis clúster realizado pone en evidencia la existencia de una tipología de empresas innovadoras andaluzas, a pesar de que las relaciones tecnológicas se reducen a la adquisición. Las diferencias entre los diferentes grupos vienen definidas por: el alcance geográfico de las relaciones tecnológicas (en lo que se refiere a la compra que es la relación predominante); la existencia de una estrategia tecnológica; y la importancia de los recursos sobre los que fundamentan sus capacidades principales.

Así se distingue, por un lado, el $25 \%$ de las empresas innovadoras andaluzas que para las que predominan las relaciones internas de compra de tecnología (por encima del $30 \%$ de media sobre el total de compras). Realizan la mayor inversión en tecnología e innovación de las firmas de la muestra, por encima del $10 \%$ de su facturación y, por tanto, siguen una estrategia tecnológica. Pero sólo la mitad están internacionalizadas. Todas ellas se localizan en aglomeraciones urbanas y se benefician de las economías generadas en estos ámbitos por la proximidad de servicios avanzados. De ahí que sean las que mayor importancia otorgan a la cualificación de sus recursos humanos como capacidad esencial porque son los responsables de captar y adaptar el Know how que circula en su entorno. Por tanto su ámbito de captación, absorción y difusión de la tecnología se basa en la proximidad geográfica y en las economías de aglomeración.

Y, por otro, el $75 \%$ de las EIA con relaciones externas a Andalucía de compra de tecnología entre las que denota que su internacionalización (casi la totalidad de estas IEA lo están) permite o faculta a las empresas acceder al mercado tecnología foráneo. Pero el origen geográfico (España, Europa, RM) del producto no está directamente vinculado al esfuerzo económico en tecnología sobre la facturación que realiza la EIA, sino que acceden a ella a través de otros canales como conexiones con clientes de mercado al realizar exportaciones y por ser EIA participadas por capital extranjero. En este último caso, la empresa matriz es la que crea los vínculos tecnológicos que terminan introduciéndose en las plantas andaluzas. Se detecta que no necesariamente este hecho implica una difusión tecnológica al resto del tejido innovador andaluz. Por un lado se observa que las grandes empresas agroalimentarias si desempeñan un importante papel en este sentido porque su mercado es amplio y complejo y por esos canales fluyen la tecnología y el conocimiento (acompañado de intensa actividad en investigación). Mientras que otras empresas que adquieren tecnología externa centran sus competencias básicas distintivas en estos productos (sin prestar mayor atención al capital humano) y en mantener unos vínculos tradicionales y duraderos con sus proveedores foráneos.

Finalmente puede decirse que Andalucía tiene rasgos de dependencia tecnológica del exterior según las cuales el mercado de tecnología regional continúa siendo muy reducido. No obstante, la compra de tecnología externa a la región favorece el aumento de la base de conocimiento siempre y cuando vaya acompañada de

ISSN: 0212-8594 ISSN-e: 2340-2776 № DOI: http://dx.doi.org/10.12795/rea.2012.i29.06 REA 29 (2012):127-157 
actividades internas de I+D para poder adaptarla a sus procesos productivos incrementando así el nivel tecnológico, aumentando la experiencia y el valor de sus recursos humanos e intensificando la capacidad de aprender para adaptarse rápidamente a los cambios que exige el mercado.

\section{BIBLIOGRAFÍA}

Alic, J. A. (1990): “Cooperation in R\&D”. Technovation. Vol. 10, no 5, págs. 319-332.

Amir, R.; Evstigneev, I. y Wooders, J. (2003): "Noncooperative Versus Cooperative R\&D with Endogenous Spillover Rates". Games and Economic Behavior. Vol. 42, no 2, págs. 183-207

Arora, A.; Fosfuri, A. y Gambardella, A. (2001): "Market for technology and their implications for corporate strategy". Indust. Corp. Change. № 10, págs. 419-451

BARNEY, J. B. (2002): "Gaining and sustaining competitive advantage". Prentice Hall. New Jersey.

Belderbo, R.; Carree, M. y LokshiN, B. (2004): "Cooperative R\&D and Firm Performance". Research Policy. Vol. 33, no 10, págs. 1.477-1.492.

Belderbos, R.; Carree, M. y Lokshin, B. (2006): "Complementarity in R\&D Cooperation Strategies". Review of Industrial Organization. Vol. 28, № 4, págs. 401-426

Boggio, F. y Dematties, G. (2002): Geografia dello sviluppo: diversità e disuguaglianze nel rapporto Nord-Sud. Torino. UTET Librería

Boix, R. (2003): Redes de ciudades y externalidades. Departamento de Economía Aplicada, Universidad Autónoma de Barcelona

Boschma, R. (2005): "Role of proximity in interaction and performance: Conceptual and emprical challenges". Regional Studies. Vol. 39 (1), págs. 41-45

Boschma, R. y Fritsch, M. (2009): "Creative Class and Regional Growth - Empirical Evidence from Seven European countries". Economic Geography. Vol. 55, págs. 391424

Camagni, R. (1992): Economia urbana. Principi e modelli teorici. La Nuova Italia Scientifica. Roma

Camagni, R. (2005): Economía urbana. Antoni Bosch. Barcelona

ISSN: 0212-8594 ISSN-e: 2340-2776 № DOI: http://dx.doi.org/10.12795/rea.2012.i29.06 REA 29 (2012):127-157 
Cano, G. (2007): "Las ciudades andaluzas en el siglo XIX. Territorio y desarrollo". Revista de Estudios Andaluces. № 26/2006, págs. 183-238.

Cano, G. (2008): “Clasificaciones urbanas en Andalucía. Las ciudades medias". Revista Estudios Andaluces. № 27, págs. 23-34.

Cassiman, B. (2009): "Complementariedades en las estrategias de innovación y el vínculo con la ciencia". Els Opuscles del CREI. №. 23, págs. 1-41.

Cassiman, B. y Veugelers, R. (2006): "In search of complementary in innovation strategy: internal R\&D and external Knowledge acquisition". Management Science. № 52, págs. 68-82

Cohen, W. y Levinthal, D. (1990): "Absorptive Capacity: A New Perspective on Learning and Innovation". Administrative Science Quarterly. Vol. 35, no 1, págs. 128-152

Comisión Europea (2000): Innovation in a Knowledge-driven economy, DG. Enterprise \& Industry, European Commission, Brussels.

COTEC (2001): Gestión de la innovación y la tecnología en la empresa. Madrid.

COTEC (2010): Mercado de tecnología. Estrategia y características. Madrid.

DematteiS, G. (1995): “Global networks, local cities”. Flux. № 15, págs. 17-33

Dierkes, M. (2003): "Visiones, Technology and Organizational Knowledge: An Analysis of the interplay between enabling factors and triggers of Knowledge Generation". En MOTHE, J. y FORAY, D. (eds.): Knowledge Management in the Innovation Process. Kluwer Academic Publishers. Boston

Escorza, P. y Valls, J. (2000): "La innovación y la empresa". Dyna, Ingeniería e Industria. № 11, págs. 39-46

Escorsa, P. y Valls, J. (2003): Tecnología e innovación en la empresa. Edicions UPC. Barcelona

Evangelista, R. y Mastrostefano, V. (2006): "Firm Size, Sectors and Countries as Sources of Variety in Innovation". Economics of Innovation and New Technologies. 15(3), págs. 247-270

Fernández de Lucio, I.; Vega Jurado, J. y Gutiérrez Gracia, A. (2008): "Estrategias de innovación de las empresas manufactureras españolas". Economistas. № 118.

ISSN: 0212-8594 ISSN-e: 2340-2776 № DOI: http://dx.doi.org/10.12795/rea.2012.i29.06 REA 29 (2012):127-157

http://www.publius.us.es/estudios_andaluces 
FernándeZ, E. (2005): Estrategia de innovación. Thomson. Madrid. 615 págs.

Garud, R. y Nayyar, P. (1994): "Transformative capacity: continual structuring by intertemporal technology transfer". Strategic Management Journal. Vol. 15, no 5, págs. 365-385

Glaeser, E. y Berry, C. (2005): "The Divergence of Human Capital Levels across Cities". KSG Working Paper No. RWP05-057. Cambridge: Harvard Institute of Economic Research, 2005

Helfat, C.; Finkelstein, S.; Mitchell, W., Peteraf, M. A; Singh, H.; Teece, D. J. y Winter, S. (2007): Dynamic Capabilities: Understanding Strategic Change in Organizations. Blackwell. Oxford

Hidalgo, A. (1999): "La gestión de la tecnología como factor estratégico de la competitividad industrial”. Economía Industrial. № 330, págs. 43-54.

Hidalgo, A.; Vizán, A. y Torres, M. (1988): "Los factores clave de la innovación tecnológica: claves de la competitividad empresarial". Dirección y Organización, DyO. № 36, págs. $5-22$

Huerta, E. y Salas, V. (2012): "La calidad del recurso empresarial en España: Indicios e implicaciones para la competitividad". La empresa en España. Papeles de Economía Española. № 132, págs. 19-37

Jordá, R. (1992): "Modernización tecnológica como estrategia de desarrollo para Andalucía". Revista de Estudios Andaluces, № 18, pp.27-67.

Jordá, R. (2009): “Empresas y sectores innovadores". En VALLÉS FERRER, V. (dir.): Economía Española. McGrawn. Madrid. Págs. 255-266

Jordá, R. y González, R. (2009): “Binomio innovación-internacionalización y su relación con la estrategia en las empresas innovadoras localizadas en Andalucía". [En línea] Scripta Nova. Revista Electrónica de Geografía y Ciencias Sociales. Vol. XIII, no 300. Barcelona. Universidad de Barcelona. <http://www.ub.es/geocrit/sn/ sn-300.htm> [Consulta: 1/04/2012].

Jordá, R. y Ruiz, F. (2009a): “Comportamiento Innovador de las Empresas Internacionalizadas por Ámbitos Territoriales en Andalucía. Flujos y Sistemas". Boletín de la A.G.E. Vol. 50, págs. 315-348

Jordá, R. y Ruiz, F. (2009b): "La internacionalización de las empresas innovadoras andaluzas. Mecanismos, evolución, fases y variables clave". Cuadernos de Geografía. № 85, págs. 23-54

ISSN: 0212-8594 ISSN-e: 2340-2776 № DOI: http://dx.doi.org/10.12795/rea.2012.i29.06 REA 29 (2012):127-157 
Jordá, R. y Ruiz, F. (2010): “La Compra de Tecnología en Andalucía. Flujos, Factores y Territorio. Las Nuevas Áreas Empresariales: Promoción y Recualificación del Suelo Industrial, Logística y Gobernanza". IV Jornadas de Geografía Económica. León. A.G.E. Págs. 1-12

Jordá, R. y Ruiz, F. (2012): "Compra tecnológica y flujos en Andalucía". Boletín de la A.G.E. Vol. 60, págs. 165-186.

Lucendo, A. L. (2009): "Recursos tecnológicos y capacidades innovadoras en las empresas industriales andaluzas". Cuadernos de Geografía. № 85, págs. 55-82

Lucendo, A. L. y González, R. (2012). Tipología de relaciones productivas y posicionamiento estratégico de las empresas innovadoras andaluzas. Revista de estudios regionales, (94), 139-166.

Malerba, F. (2004): Sectoral Systems of Innovation: Concepts, Issues and Analyses of Six Major Sectors in Europe. Cambridge University Press. Cambridge http://dx.doi.org/10.1017/CBO9780511493270

Noguera, J. y Esparcia, J. (2008): Nuevos factores de Desarrollo Territorial. Publicacions de la Universitat de València

OCDE (2009a): Science, Technology and Industry Scoreboard 2009. Paris

OCDE (2009b): How Regions Grow. Paris

OCDE y EUROSTAT (2005): Manual de Oslo. Guía para la recogida e interpretación de datos sobre innovación. Págs. 194

O’Kean, J.Mạ; Palma; L.A; Martín, J.L. (1989): "Cambio tecnológico y función empresarial: reflexiones sobre la economía andaluza". Revista de Estudios Andaluces, no 12 , pp. 1-14.

ONUDI (1984): Autosuficiencia tecnológica de los países en desarrollo: hacia la reformulación de estrategias operativas. Serie "Desarrollo y Transferencia de tecnología”. №15. Naciones Unidas. Nueva York

Pavitt, K. (1984): "Sectoral Patterns of Technical Change: Towards a Taxonomy a Theory". Research Policy. Vol. 13, no 6, págs. 343-373

Pavón, J. y Hidalgo, A. (1997): Gestión e innovación: Un enfoque estratégico. Ediciones Pirámide. Madrid.

Pérez, F. (dir.) (2011): Crecimiento y competitividad. Trayectoria y perspectiva de la economía española. Fundación BBVA-IVIE, Madrid.

ISSN: 0212-8594 ISSN-e: 2340-2776 № DOI: http://dx.doi.org/10.12795/rea.2012.i29.06 REA 29 (2012):127-157 
Porter, M. (2009): Estrategia competitiva. Técnicas para el análisis de la empresa y sus competidores. Ediciones Pirámide. Madrid. Págs. 455

Porter, M. E. (1990): The Competitive Advantage of Nations. Free Press. New York

Rezzónico, R. y Muñoz, G. (2009): “Claves para la competitividad sistémica local y regional: innovación para el desarrollo, un estado del arte". III Congreso Internacional de Gestión del Conocimiento / XII Taller de Gestión Tecnológica en la Industria (GESTEC 2009).

Ruiz, F. (2005): "Espacio relacional, proceso innovador y difusión territorial de la innovación en Andalucía". Geographicalia. № 47, págs. 111-136.

Sánchez, A. y Hernández, E. (2006): “Análisis de cluster para definir territorios a investigar sobre el servicio de auditoría. Principios y fundamentos teóricos para su aplicación". Investigación de Mercados, Gestopolis. [En línea] <http:/www.gestiopolis.com/canales6/mkt/investigacion-demercados-yauditoria.htm\#mas-autor> [Consultado: 10/03/2012].

Santamaría, L. y Rialp, J. (2007): “Determinantes de la elección del socio tecnológico: especificidades sectoriales y de tamaño", Cuadernos Económicos de ICE. № 73, págs. 37-64

Soete, L. y Miozzo, M. (1989): Trade and Development in Services: A Technological Perspective. Working Paper no 89. MERIT. Maastricht. Págs. 62

Vega Jurado, J.; Gutiérrez Gracia, A. y Fernández de Lucio, I. (2008): “¿Cómo innovan las empresas españolas? Una evidencia empírica". Journal of Technology Management \& Innovation. № 3, págs. 100-111.

Vega Jurado, J.; Gutiérrez-Gracia, A. y Fernández de Lucio, I. (2009a): "Estrategias de adquisición de conocimiento en los procesos de innovación empresarial". Arbor. Vol. 185 (738), págs. 781-791

Vega Jurado, J.; Gutiérrez Gracia, A. y Fernández de Lucio, I. (2009b): "La Relación entre las Estrategias de Innovación: Coexistencia o Complementariedad". Journal of Technology Management \& Innovation. Vol. IV, no 3, págs. 74-88. [En línea] $<$ http://www.scielo.cl/scielo.php?script= sci_arttext\&pid=S0718-

27242009000300007\&lng=es\&nrm=iso> [Consulta 16/02/2011]

Villar, C.; Pla Barber, J. y Alegre Vidal, J. (2012): "Estrategias de innovación y exportación: Un análisis conjunto desde la perspectiva del conocimiento" La empresa en España. Papeles de Economía Española. № 132, págs. 97-108.

ISSN: 0212-8594 ISSN-e: 2340-2776 № DOI: http://dx.doi.org/10.12795/rea.2012.i29.06 REA 29 (2012):127-157 